$$
\begin{aligned}
& \text { ANL/ET/CP-94202 } \\
& \text { CONF-970758- }
\end{aligned}
$$

Processing Considerations for Adding Nanometer-Scale Oxides to Enhance Flux Pinning in High-Temperature Superconductors*

Y. Xu

Mankato State University, Mankato, Minnesota 56002 USA

K. C. Goretta, M. M. Cuber, M. L. Burdt, L. R. Feng, Nan Chen, U. Balachandran

Argonne National Laboratory, Argonne, Illinois 60439 USA

$$
\text { and M. Xu }
$$

University of Chicago, Chicago, Illinois 60637 USA

July 1997

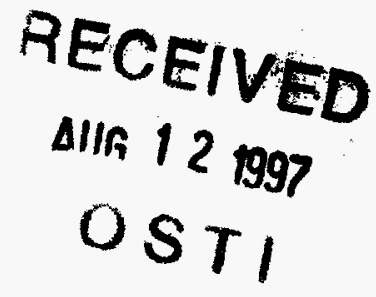

The submitted manuscript has been created by the University of Chicago as Operator of Argonne National Laboratory ("Argonne") under Contract No. W-31-109-ENG-38 with the U.S. Department of Energy. The U.S. Government retains for itself, and others acting on its behalf, a paid-up, nonexclusive, irrevocable worldwide license in said article to reproduce, prepare derivative works, distribute copies to the public, and perform publicly and display publicly, by or on behalf of the Covernment.

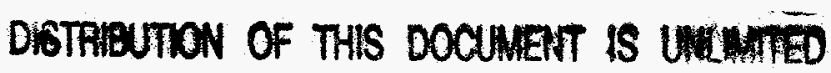
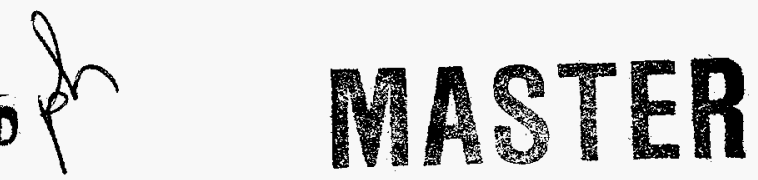

Submitted to Proceedings of the 1997 International Cryogenic Materials Conference, Portland, OR, July 28-August 1, 1997.

*Work supported by the U.S. Department of Energy (DOE), Energy Efficiency and Renewable Energy, as part of a DOE program to develop electric power technology, and by the Argonne Division of Educational Programs with funding from DOE, under Contract W-31-109-Eng-38; and by the National Science Foundation Office of Science and Technology Centers, under Contract DMR 91-20000. 


\section{DISCLAIMER}

This report was prepared as an account of work sponsored by an agency of the United States Government. Neither the United States Government nor any agency thereof, nor any of their employees, makes any warranty, express or implied, or assumes any legal liability or responsibility for the accuracy, completeness, or usefulness of any information, apparatus, product, or process disclosed, or represents that its use would not infringe privately owned rights. Reference herein to any specific commercial product, process, or service by trade name, trademark, manufacturer, or otherwise does not necessarily constitute or imply its endorsement, recommendation, or favoring by the United States Government or any agency thereof. The views and opinions of authors expressed herein do not necessarily state or reflect those of the United States Government or any agency thereof. 


\section{DISCLAMIER}

Portions of this document mey be illegible in electronic image prodnets. Impges are produced from the best available original docement. 


\title{
PROCESSING CONSIDERATIONS FOR ADDING NANOMETER-SCALE OXIDES TO ENHANCE FLUX PINNING IN HIGH-TEMPERATURE SUPERCONDUCTORS
}

\author{
Y. Xu, ${ }^{1,2}$ K. C. Goretta, ${ }^{1}$ M. M. Cuber, ${ }^{1}$ M. L. Burdt, ${ }^{1}$ \\ L. R. Feng, ${ }^{1} \mathrm{Nan}$ Chen, ${ }^{1} \mathrm{U}$. Balachandran, ${ }^{1}$ and $\mathrm{M}$. $\mathrm{Xu}^{3}$ \\ ${ }^{1}$ Argonne National Laboratory, Argonne, IL 60439 U.S.A. \\ 2Mankato State University, Mankato, MN 56002 U.S.A. \\ ${ }^{3}$ University of Chicago, Chicago, IL 60637 U.S.A.
}

\begin{abstract}
Several nanometer-scale oxide inclusions were added to $\mathrm{Bi}_{2} \mathrm{Sr}_{2} \mathrm{CaCu}_{2} \mathrm{O}_{\mathrm{x}}$ hightemperature superconductors to determine their effectiveness in creating intragranular fluxpinning sites. Powder pellets were fabricated and heat treated by partial-melt processing. Effects of the additives on melting response, superconducting properties, and microstructural development were examined. $\mathrm{Al}_{2} \mathrm{O}_{3}$ additions exhibited the most promise for forming stable pinning centers, $\mathrm{ZrO}_{2}$ and $\mathrm{SnO}_{2}$ additions were moderately promising, $\mathrm{TiO}_{2}, \mathrm{Fe}_{2} \mathrm{O}_{3}$, and $\mathrm{ZnO}$ additions were less promising, and $\mathrm{Y}_{2} \mathrm{O}_{3}$ additions destroyed superconductivity.
\end{abstract}

\section{INTRODUCTION}

Nanometer-scale second phases have proved to be effective flux-pinning centers in high-temperature superconductors. Examples of improved flux pinning in the presence of second phases include $\mathrm{Y}_{2} \mathrm{BaCuO}_{5}$ in $\mathrm{YBa}_{2} \mathrm{Cu}_{3} \mathrm{O}_{\mathrm{x}}, 1$ carbon-rich phases in many superconductors, ${ }^{2,3} \mathrm{BaAl}_{2} \mathrm{O}_{4}$ in $\mathrm{TlBa}_{2} \mathrm{Ca}_{2} \mathrm{Cu}_{3} \mathrm{O}_{\mathrm{x}},{ }^{4}$ and $(\mathrm{Ca}, \mathrm{Cu}) \mathrm{O}_{\mathrm{x}}$ in $\mathrm{Bi}_{2} \mathrm{Sr}_{2} \mathrm{CaCu}_{2} \mathrm{O}_{\mathrm{x}} .{ }^{5}$ $\mathrm{Bi}$-based superconductors are most in need of improved flux pinning 6 at temperatures that approach $77 \mathrm{~K}$, and substantial success has now been achieved with these materials. ${ }^{7-14}$

In this work, we have added nanometer-scale oxides directly to $\mathrm{Bi}_{2} \mathrm{Sr}_{2} \mathrm{CaCu}_{2} \mathrm{O}_{\mathrm{x}}$. Although addition of nearly unreactive particles, such as $\mathrm{SrZrO}_{3}$ or $\mathrm{MgO}$, would be ideal, $7,8,12,13$ we have added reactive particles such as $\mathrm{Al}_{2} \mathrm{O}_{3}$ or $\mathrm{TiO}_{2}$. The decision to do so was based on several factors: such oxides are readily available from commercial sources at reasonable prices; $9,15,16$ they exhibit relatively tight particle-size distributions and their size can be tailored; 16 and they can be obtained in nearly spherical shapes, and, therefore, exhibit minimal agglomeration. ${ }^{4}$ Also, $\mathrm{Al}_{2} \mathrm{O}_{3}$ or $\mathrm{TiO}_{2}$ have previously exhibited promise in enhancing flux pinning in high-temperature superconductors. $4,9,15$ Any commercial process for flux-pinning enhancement will require that the second phase be relatively uniform in size and very well distributed within the superconductor grains. We believe that these requirements can be met by use of nanometer-scale oxides that have been grown by vapor-phase methods. ${ }^{16,17}$ 
Phase equilibria in superconductor systems are complex, and it can be very difficult to predict reactions between superconductors and second phases. We therefore approached our work from the point of view of nanometer-scale oxide availability. Simple oxides were added to $\mathrm{Bi}_{2} \mathrm{Sr}_{2} \mathrm{CaCu}_{2} \mathrm{O}_{x}$ and their effects on superconducting transition and microstructure were examined. Our investigations focused only on identifying promising oxide additives. Before effects on pinning can be studied meaningfully, compositions and processing methods must be optimized.

\section{EXPERIMENTAL PROCEDURES}

$\mathrm{Bi}_{1.88} \mathrm{Sr}_{2.11} \mathrm{CaCu}_{2} \mathrm{O}_{\mathbf{x}}(\mathrm{Bi}-2212)$ powder was synthesized from mixtures of oxides and carbonates. 18 This composition was chosen because we expected $\mathrm{Sr}$ to react with the additives, and, in the second stage of this project, we intend to convert the $\mathrm{Bi}-2212$ into $(\mathrm{Bi}, \mathrm{Pb})_{2} \mathrm{Sr}_{2} \mathrm{Ca}_{2} \mathrm{Cu}_{3} \mathrm{O}_{\mathrm{x}}$ by addition of $\mathrm{PbO}, \mathrm{CaO}$, and $\mathrm{CuO}$. X-ray diffraction (XRD) and differential thermal analysis (DTA) revealed that the $\mathrm{Bi}-2212$ was virtually phase pure. All DTA studies were conducted in air at a heating rate of $300^{\circ} \mathrm{C} / \mathrm{h}$, with $\mathrm{Al}_{2} \mathrm{O}_{3}$ used for crucibles and the standard.

Nanometer-scale $\mathrm{Al}_{2} \mathrm{O}_{3}, \mathrm{TiO}_{2}, \mathrm{Fe}_{2} \mathrm{O}_{3}, \mathrm{ZnO}, \mathrm{Y}_{2} \mathrm{O}_{3}, \mathrm{ZrO}$, and $\mathrm{SnO}_{2}$ powders were obtained from Nanophase Technologies Corporation (Burr Ridge, IL). The powders were produced by a vapor-phase reaction and consisted of nearly spherical grains. 4,16 Each powder was mixed in a 1:4 molar ratio of oxide:Bi-2212 by vibratory milling for $1 \mathrm{~h}$ in isopropyl alcohol. 4,9 Powder mixtures were then dried on a hot plate while being stirred. The dried powders were pressed into $1.5-\mathrm{g}, 12.7-\mathrm{mm}$-diameter pellets, which were stored in a desiccator until needed.

To aid in microstructural examination, similar pellets were prepared with micrometerscale oxide inclusions. These specimens were used to identify reaction products.

All heat treatments were conducted in air, with the pellets placed in $\mathrm{Ag}$ crucibles. Each heat treatment consisted of rapid heating to a temperature $\approx 20^{\circ} \mathrm{C}$ greater than the onset of melting indicated by DTA, holding at temperature for $0.2-1.0 \mathrm{~h}$, and then cooling either by an air quench, or slowly, to nucleate and grow the $\mathrm{Bi}-2212$ phase,9,19 (Bulk $\mathrm{Bi}_{2} \mathrm{Sr}_{2} \mathrm{CaCu}_{2} \mathrm{O}_{\mathrm{X}}$ superconductors are invariably partial-melt-processed to achieve high transport $J_{c}$ values. ${ }^{19,20}$ ) DTA revealed that, in general, the oxide additions induced a slight broadening of the melting endotherm (Fig. 1). Approximate onset temperatures of significant melting $\left(T_{m}\right)$ for each powder are listed in Table 1 .

A commercial SQUID magnetometer was used to measure the superconducting transition temperature $\left(T_{c}\right)$ of the slowly cooled samples. The samples were examined by $\mathrm{XRD}$, scanning electron microscopy (SEM), and energy dispersive spectroscopy (EDS) for microstructural analysis.

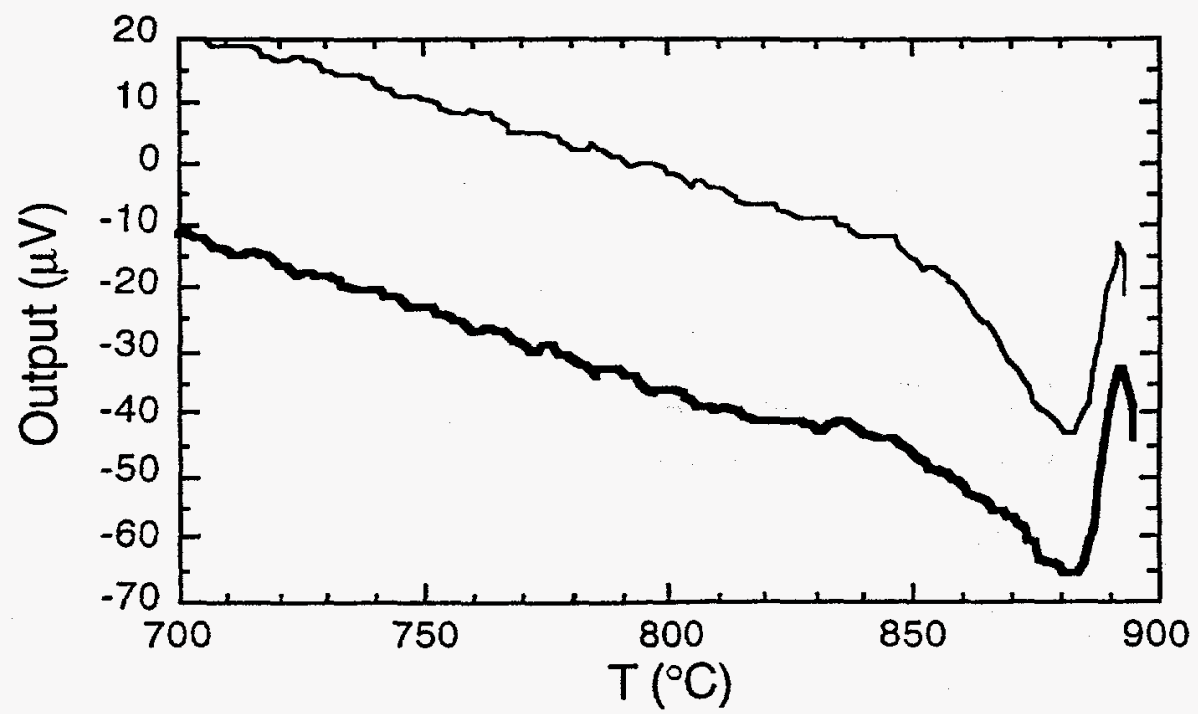

Figure 1. Representative DTA data for $\mathrm{Bi}-22 \mathrm{l} 2$ (fine line) and $\mathrm{Bi}-2212+\mathrm{Al}_{2} \mathrm{O}_{3}$ (bold line). 
Table 1. Onset of melting in air as determined by DTA.

\begin{tabular}{ll}
\hline Composition & $\mathrm{T}_{\mathrm{m}}\left({ }^{\circ} \mathrm{C}\right)$ \\
\hline $\mathrm{Bi}-2212$ & 854 \\
$\mathrm{Bi}-2212+\mathrm{Al}_{2} \mathrm{O}_{3}$ & 846 \\
$\mathrm{Bi}-2212+\mathrm{TiO}_{2}$ & 845 \\
$\mathrm{Bi}-2212+\mathrm{Fe}_{2} \mathrm{O}_{3}$ & 854 \\
$\mathrm{Bi}-2212+\mathrm{ZnO}$ & 852 \\
$\mathrm{Bi}-2212+\mathrm{Y}_{2} \mathrm{O}_{3}$ & $854^{*}$ \\
$\mathrm{Bi}-2212+\mathrm{ZrO}_{2}$ & 864 \\
$\mathrm{Bi}-2212+\mathrm{SnO}_{2}$ & 869 \\
\hline
\end{tabular}

*The first melt was small and did not appear to correspond to substantial melting of the $\mathrm{Bi}-2212$ phase.

\section{RESULTS AND DISCUSSION}

Rapid heating to a partial-melt temperature, followed by slow cooling to grow superconductor grains in which nanometer-scale oxides are enveloped, has proved to be successful in creating stable flux-pinning centers in $\mathrm{YBa}_{2} \mathrm{Cu}_{3} \mathrm{O}_{x}$ and $\mathrm{TIBa}_{2} \mathrm{Ca}_{2} \mathrm{Cu}_{3} \mathrm{O}_{\mathrm{x}}{ }^{4,9,15}$ Key features of the microstructural-development sequence are (a) suppression of a eutectic reaction by rapid heating to a melt, (b) rapid reaction in the melt with $\mathrm{Ba}$ to form a stable oxide such as $\mathrm{BaTiO}_{3}$ or $\mathrm{BaAl}_{2} \mathrm{O}_{4}$, (c) avoidance of coarsening of the second phase, and (d) incorporation of the nanometer-scale phase into growing superconductor grains during cooling. Because the molar concentration of any additive is high, it is imperative that the oxide additive not exhibit a strong tendency to substitute directly into the superconductor lattice. If it does, overdoping and reduced superconducting properties are generally the result.

We are looking for an oxide that when added to $\mathrm{Bi}-2212$ will react as, for example, $\mathrm{Al}_{2} \mathrm{O}_{3}$ reacts with $\mathrm{TlBa} \mathrm{Ca}_{2} \mathrm{Cu}_{3} \mathrm{O}_{\mathrm{x}} \cdot{ }^{4}$ Goals for the additive are that it alter peritectic-melt and crystal-growth responses minimally, have little deleterious effect on $T_{c}$, and form a stable phase, probably by reaction with $\mathrm{Sr}$ or $\mathrm{Ca}$. Of the oxides selected, only $\mathrm{Y}_{2} \mathrm{O}_{3}$ failed to achieve any of the goals. Minor substitution of $Y$ into the $\mathrm{Bi}-2212$ lattice can enhance flux pinning. 21 However, our method of addition caused a complete change of the melting characteristics, with most of the melting being driven to a higher temperature, suppression of $\mathrm{Bi}-2212$ crystallization after melting, and complete loss of superconductivity at $\mathrm{T} \geq 4.2 \mathrm{~K}$. All other oxide additions merited closer examination.

$\mathrm{T}_{\mathrm{c}}$ values of the slowly cooled pellets are shown in Table 2 . No attempt was made to optimize $\mathrm{T}_{c}$ by changing oxygen stoichiometry. Although $\mathrm{ZrO}_{2}$ and $\mathrm{SnO}_{2}$ had no appreciable effect on the onset $\mathrm{T}_{c}, \mathrm{Al}_{2} \mathrm{O}_{3}$ induced a slight decrease in $\mathrm{T}_{\mathrm{c}}$, and $\mathrm{TiO}_{2}$, $\mathrm{Fe}_{2} \mathrm{O}_{3}$, and $\mathrm{ZnO}$ decreased $\mathrm{T}_{\mathrm{c}}$ and broadened the transition width significantly. Based on $\mathrm{T}_{\mathrm{c}}$ values only, $\mathrm{Al}_{2} \mathrm{O}_{3}, \mathrm{ZrO}_{2}$, and $\mathrm{SnO}_{2}$ nanometer-scale additions appear to hold promise as additives to $\mathrm{Bi}-22 \mathrm{l} 2$ for partial-melt processing.

SEM/EDS studies revealed clear differences for the effects of the various oxide additives on microstructural development. Representative microstructures of specimens with micrometer-scale oxides that were air quenched after $0.25 \mathrm{~h}$ at the partial melt temperature are shown in Fig. 2.

Table 2. $T_{c}$ values for melt-processed pellets that were cooled slowly from a partial melt.

\begin{tabular}{lll}
\hline Composition & $\mathrm{T}_{\mathrm{c}, \text { onset }}(\mathrm{K})$ & $\mathrm{T}_{\mathrm{c} \text {. midpoint }}(\mathrm{K})$ \\
\hline $\mathrm{Bi}-2212$ & 88 & 84 \\
$\mathrm{Bi}-2212+\mathrm{Al}_{2} \mathrm{O}_{3}$ & 82 & 73 \\
$\mathrm{Bi}-2212+\mathrm{TiO}_{2}$ & 74 & 52 \\
$\mathrm{Bi}-2212+\mathrm{Fe}_{2} \mathrm{O}_{3}$ & 45 & 29 \\
$\mathrm{Bi}-2212+\mathrm{ZnO}_{\mathrm{O}}$ & 74 & 58 \\
$\mathrm{Bi}-2212+\mathrm{Y}_{2} \mathrm{O}_{3}$ & Not superconducting & - \\
$\mathrm{Bi}-2212+\mathrm{ZrO}_{2}$ & 88 & 78 \\
$\mathrm{Bi}-2212+\mathrm{SnO}_{2}$ & 88 & 82 \\
\hline
\end{tabular}



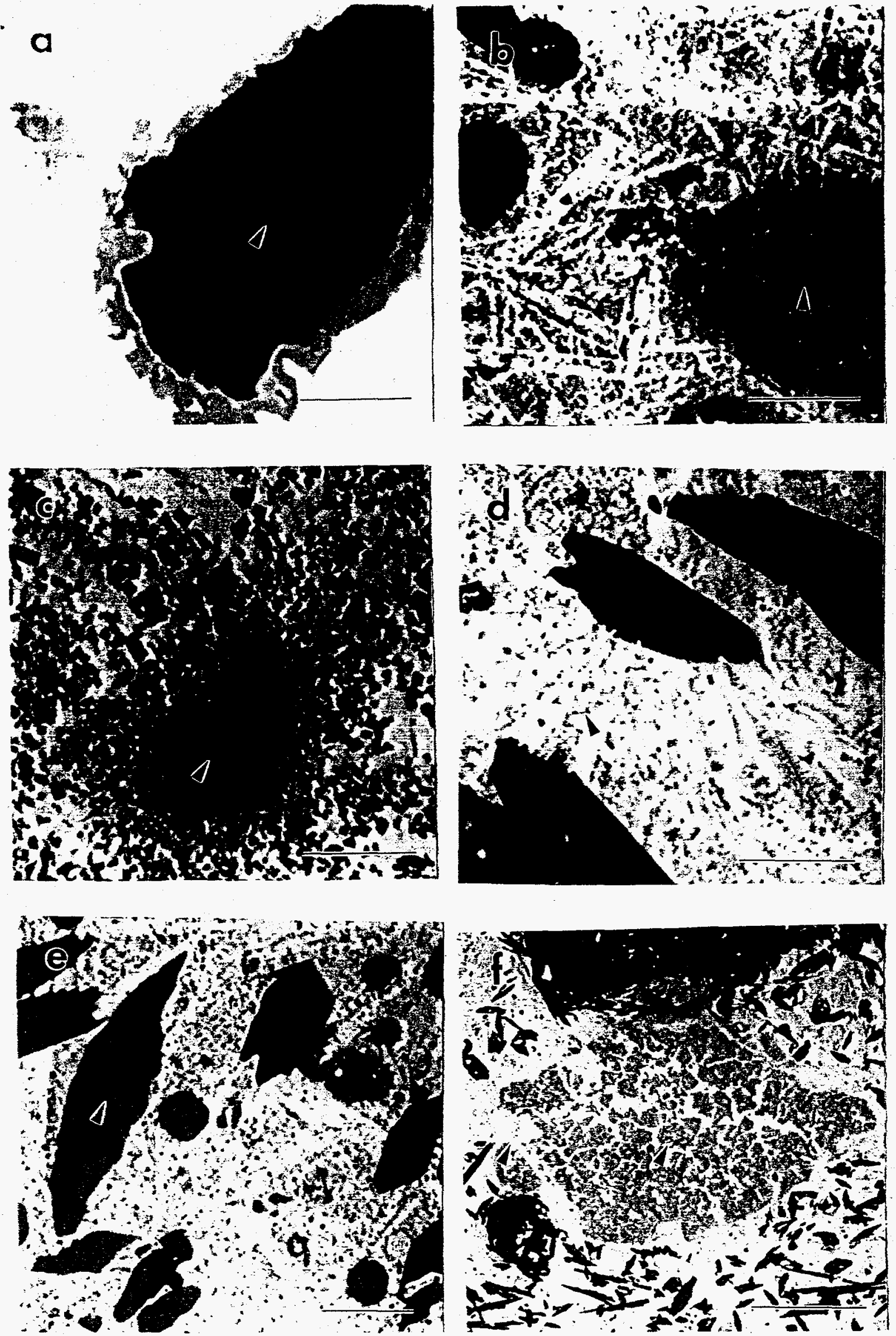

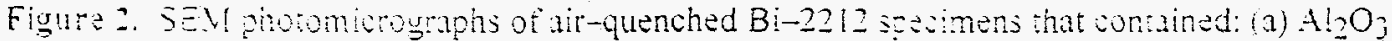

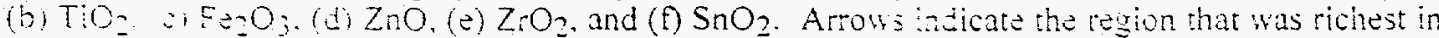

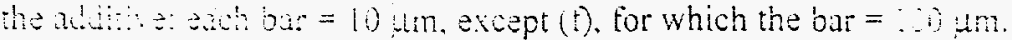


The $\mathrm{Al}_{2} \mathrm{O}_{3}$-containing specimen (Fig. 2a) exhibited evidence of formation of stable reaction products. A dark ring of $(\mathrm{Sr}, \mathrm{Ca})_{2} \mathrm{AlO}_{\mathrm{x}}$ was present around each $\mathrm{Al}_{2} \mathrm{O}_{3}$ particle. In most cases, a thinner, lighter-colored, partial ring, of approximate composition $\mathrm{Al}_{0.5}(\mathrm{Sr}, \mathrm{Ca})_{0.4} \mathrm{Bi}_{0.1} \mathrm{O}_{\mathrm{x}}$, was also present. EDS analyses indicated that the concentration of $\mathrm{Al}$ in the matrix of the solidified melt was $\approx 1 \%$. The dominant alkaline earth cuprate phase in the quenched sample was $(\mathrm{Sr}, \mathrm{Ca}) \mathrm{CuO}_{2}$. This phase was smaller than is generally observed in melt-processed $\mathrm{Bi}-2212 ; 19$ the refining effect of $\mathrm{Al}_{2} \mathrm{O}_{3}$ additions on alkaline earth cuprates in $\mathrm{Bi}_{2} \mathrm{Sr}_{2} \mathrm{CaCu}_{2} \mathrm{O}_{x}$ has been reported. 22

Heating at the maximum temperature for $1 \mathrm{~h}$ caused the $(\mathrm{Sr}, \mathrm{Ca})_{2} \mathrm{AlO}_{\mathrm{x}}$ phase to break up and diffuse away from the parent $\mathrm{Al}_{2} \mathrm{O}_{3}$, rather like icebergs separating from a glacier; however, individual islands did not grow significantly. The $\mathrm{Al}_{2} \mathrm{O}_{3}: \mathrm{Bi}-2212$ system exhibited a response close to that desired: peritectic melting was relatively unaffected and, as a benefit, refinement of the $(\mathrm{Sr}, \mathrm{Ca}) \mathrm{CuO}_{2}$ phase occurred; the $\mathrm{T}_{\mathrm{c}}$ value was slightly depressed, but the transition remained sharp; and, although two $\mathrm{Al}$-containing phases were formed, the $(\mathrm{Sr}, \mathrm{Ca})_{2} \mathrm{AlO}_{\mathrm{x}}$ was dominant and appeared to be stable.

Given the stability of $\mathrm{SrTiO}_{3}$, one would expect that the $\mathrm{TiO}_{2}: \mathrm{Bi}-2212$ system would be similar to the $\mathrm{Al}_{2} \mathrm{O}_{3}: \mathrm{Bi}-2212$ system. This did not prove to be so. Although some $(\mathrm{Sr}, \mathrm{Ca}) \mathrm{TiO}_{\mathrm{x}}$ formed, $\mathrm{Ti}$ exhibited a strong tendency to dissolve into the melt (Fig. $\left.2 \mathrm{~b}\right)$. For this system, the dominant alkaline earth cuprate was approximately $(\mathrm{Sr}, \mathrm{Ca})_{2} \mathrm{Cu}_{3} \mathrm{O}_{x}$, with $\approx 1 \% \mathrm{Ti}$ incorporated. The quenched matrix consisted of lighter and darker regions, with the darker regions containing $\approx 5 \% \mathrm{Ti}$. This microstructure strongly suggests that significant concentrations of $\mathrm{Ti}$ would be present in any $\mathrm{Bi}-2212$ that formed. Small concentrations of $\mathrm{Ti}$ on the $\mathrm{Bi}-2212$ lattice can be beneficial, 23 but our concentrations appear to be too high. $T_{c}$ was strongly depressed and, in earlier work, we reported that little enhancement of flux pinning was obtained. 13 Similar effects from overdoping have been reported by Grivel et al. 24 Although $\mathrm{TiO}_{2}$ additions did not prove to be effective in these studies, it may be that, given the inherent stability of $\mathrm{SrTiO}_{3}$, some other set of processing conditions, for example use of a different oxygen partial pressure or perhaps $\mathrm{Sr}$-rich $\mathrm{Bi}-2212$ compositions, could lead to enhanced flux pinning.

Additions of $\mathrm{Fe}_{2} \mathrm{O}_{3}$ produced several microstructural effects (Fig. 2c). Adjacent to the $\mathrm{Fe}_{2} \mathrm{O}_{3}$ particles, a phase formed with approximate composition $(\mathrm{Sr}, \mathrm{Ca})_{0.5} \mathrm{Fe}_{\mathrm{x}} \mathrm{Cu}_{\mathrm{y}} \mathrm{O}_{\mathrm{z}}$, where $x \approx 0.2-0.35$ and $y \approx 0.15-0.3$. This phase was not as stable as the (Sr,Ca) ${ }_{2} \mathrm{AlO} x$ phase was in the $\mathrm{Al}_{2} \mathrm{O}_{3}$-containing specimens; none was retained in the slowly cooled specimens. Other phases present in the melt were $\mathrm{CuO}$ and $(\mathrm{Sr}, \mathrm{Ca})_{2} \mathrm{Cu}_{3} \mathrm{O}_{\mathrm{x}}$. The solidified melt contained $\approx 4-8 \% \mathrm{Fe}$. Fe has been shown to substitute for $\mathrm{Cu}$ in superconductor lattices. The depression of $T_{c}$ may have been caused by such substitution.

$\mathrm{ZnO}$ additions produced no single identifiable $\mathrm{Zn}$-rich phase (Fig. 2d). Regions of solidified melt contained 1-2\% $\mathrm{Zn}$ (light shade) and 9-10\% Zn (dark shade). $(\mathrm{Sr}, \mathrm{Ca})_{2} \mathrm{Cu}_{3} \mathrm{O}_{\mathrm{x}}$ was the dominant alkaline earth cuprate. For flux pinning, $\mathrm{ZnO}$ additions appear to be more suitable to solid-solution alloying schemes than to the production of distinct nanometer-scale second phases.

Nanometer-scale $\mathrm{SrZrO}_{3}$ has been reported to impart enhanced flux pinning in $\mathrm{Bi}_{2} \mathrm{Sr}_{2} \mathrm{CaCu}_{2} \mathrm{O}_{\mathrm{x}} \cdot 7,8,25$ Although we could identify a distinct $(\mathrm{Sr}, \mathrm{Ca}, \mathrm{Cu}) \mathrm{ZrO}_{\mathbf{x}}$ phase within the melt (Fig. $2 \mathrm{e}$ ), it was not prevalent and the melt contained $4-8 \%$ dissolved $\mathrm{Zr}$. Thus, although presence of a fine-scale alkaline earth zirconate can yield enhanced flux pinning, the processing scheme of rapid heating to a partial-melt temperature does not seem to be ideal to take advantage of the possibilities. High concentrations of $\mathrm{Zr}$ in a melt will probably promote coarsening of any zirconate second phase. 4,9 Preliminary measurements of magnetic hysteresis in a set of our $\mathrm{ZrO}_{2}: \mathrm{Bi}-2212$ specimens indicated no enhancement of flux pinning at temperatures to as low as $5 \mathrm{~K} .26$

Additions of $\mathrm{SnO}_{2}$ to $\mathrm{Bi}-2212$ induced a complex response. A phase of approximate composition ( $\mathrm{Sr}, \mathrm{Ca})_{3} \mathrm{SnO}_{\mathrm{x}}$ was identified (Fig. 2f). Enhanced flux pinning in Sn-doped $(\mathrm{Bi}, \mathrm{Pb})_{2} \mathrm{Sr}_{2} \mathrm{Ca}_{2} \mathrm{Cu}_{3} \mathrm{O}_{\mathrm{x}}$ has previously been ascribed to this phase. $27 \mathrm{Sn}$-doping has, however, also been correlated with broadening of the superconducting transition and with a decrease in the fraction of the high- $T_{c}$ phase. ${ }^{28}$ The solidified melt in our Sn-doped specimen generally contained $\approx 10 \% \mathrm{Sn}$, with some regions containing up to $\approx 30 \% \mathrm{Sn}$. It appears that $\mathrm{Sn}$ is likely to form a stable alkaline earth phase and to substitute onto the $\mathrm{Bi}-2212$ lattice. As no depression in $\mathrm{T}_{c}$ was observed, additions of nanometer-scale $\mathrm{SnO}_{2}$ may hold promise. However, as was the case with our $\mathrm{ZrO}_{2}$ additions, preliminary

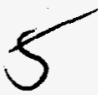


magnetic hysteresis measurements indicated no enhancement of tlux pinning in our $\mathrm{Sn}-$ doped specimens.

When couled sluwly, all jpecimens other than the one that contained $\mathrm{Y}_{2} \mathrm{O}_{3}$ consisted primarily of the $\mathrm{Bi}_{2} \mathrm{Sr}_{2} \mathrm{CaCu}_{2} \mathrm{O}_{x}$ phase (Fig. 3). Of all the dopant-containing second phases, $(\mathrm{Sr}, \mathrm{Ca})=+1 \mathrm{O}_{\mathrm{x}}$ was the only one that proved to be highly stable and present in large concentrations in a slowly cooled pellet. As stated previously, other processing conditions could perhaps lead to different results. For the approach taken here, nanometer-scale $\mathrm{Al}_{2} \mathrm{O}_{3}$ additions appear to offer the most promise for enhancing controlled fiux pinning in melt-processed $\mathrm{Bi}_{2} \mathrm{Sr}_{2} \mathrm{CaCu}_{2} \mathrm{O}_{\mathrm{x}}$. We have reported some success with this system. ${ }^{9}$ Although the other oxide additives may prove useful, processing will be complicated by the fact that, in general, the oxides appear to form second phases and substitute into the superconductor lattice.

\section{SUMIMARY}

Micrometer-scale and nearly spherical nanometer-scale $\mathrm{Al}_{2} \mathrm{O}_{3}, \mathrm{TiO}_{2}, \mathrm{Fe}_{2} \mathrm{O}_{3}, \mathrm{ZnO}$, $\mathrm{Y}_{2} \mathrm{O}_{3}, \mathrm{ZrO}_{2}$, and $\mathrm{SnO}_{2}$ particles were added in a $1: 4$ molar ratio to $\mathrm{Bi}-2212$. Resultant cold-pressed pellets were partial-melt processed in air and then either quenched in air or cooled slowly to form the superconducting phase. These oxide additions were selected on the basis of availability of high-quality supplies. Goals of the study were to determine whether the oxide additions formed stable second phases or substituted into the superconductor lattice, and whether the oxide additions had an effect on the superconducting transition temperature. $\mathrm{Al}_{2} \mathrm{O}_{3}$ additions, which exhibited the most promise for forming stable pinning centers, also induced a small decrease in $\mathrm{T}_{\mathrm{c}} . \mathrm{ZrO}_{2}$ and $\mathrm{SnO}_{2}$ appeared to form stable second phases, but also may have substituted partially into the superconductor lattice; however, $T_{c}$ values were nearly unchanged by these additions. $\mathrm{TiO}_{2}, \mathrm{Fe}_{2} \mathrm{O}_{3}$, and $\mathrm{ZnO}$ additions led to significant decreases in $\mathrm{T}_{c}$, probably because of lattice substitution. $\mathrm{Y}_{2} \mathrm{O}_{3}$ additions altered the melting response of $\mathrm{Bi}-2212$ significantly and prevented formation of the superconducting phase.
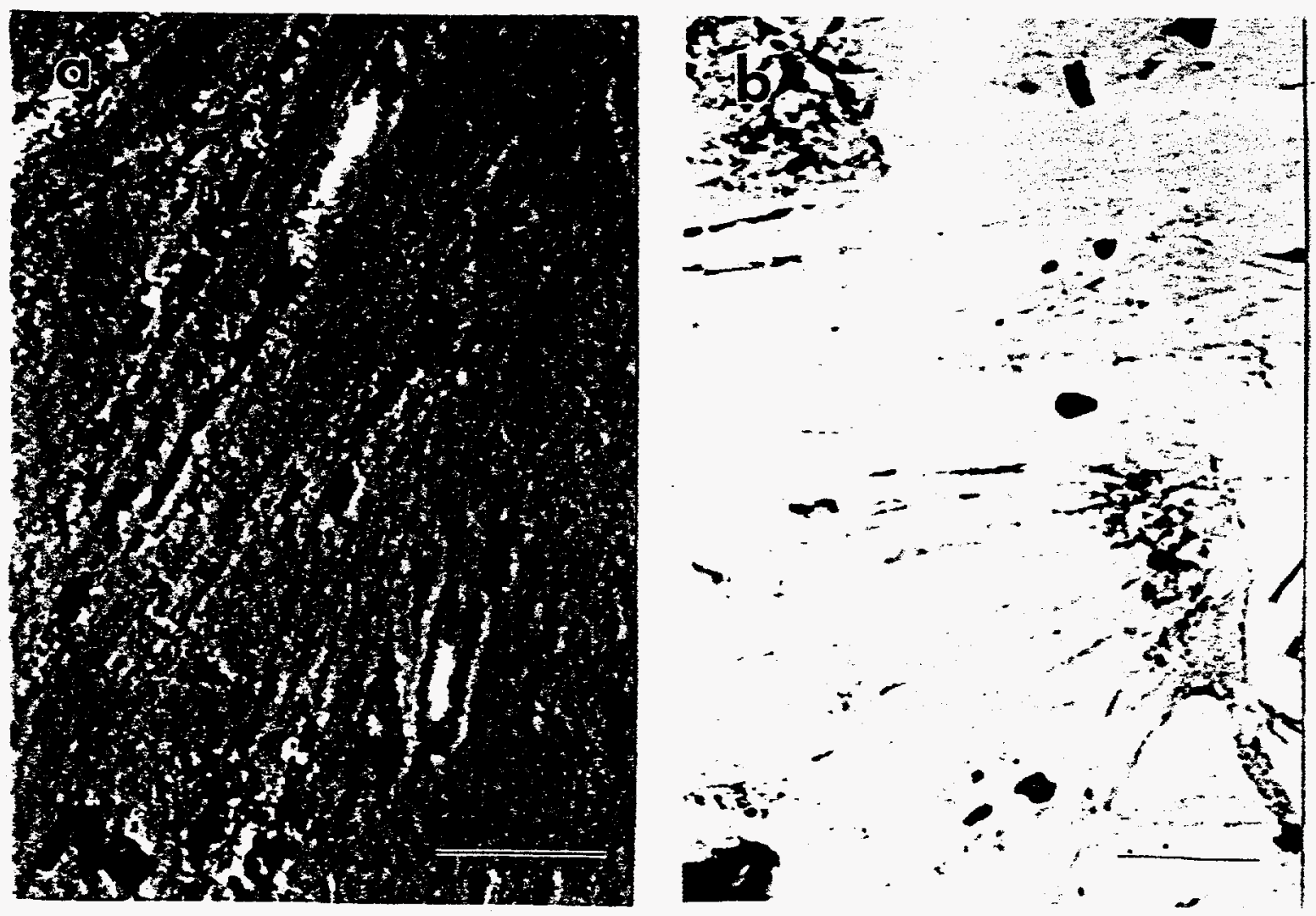

Figure 3. Representative SEM photomicrographs of slowly cooled Bi-2212 specimens that contained (a) $\mathrm{Al}_{2} \mathrm{O}_{3}$ and (b) $\mathrm{SnO}_{2}$. The light-colored regions are $\mathrm{Ag}$, which dissolved from the crucible. Elongated $\mathrm{Bi}-22 \mathrm{12}$ grains are dominant and little second phase is evident. Bars $=10 \mu \mathrm{m}$. 


\section{ACKNOWLEDGMENTS}

This work was supported by the U.S. Department of Energy (DOE), Energy Efficiency and Renewable Energy, as part of a DOE program to develop electric power technology, and by the Argonne Division of Educational Programs with funding from DOE, under Contract W-31-109-Eng-38; and by the National Science Foundation Office of Science and Technology Centers, under Contract DMR 91-20000.

\section{REFERENCES}

1. M. Murakami, N. Sakai, T. Higuchi, and S. I. Yoo, Melt-processed light rare earth elementBa-Cu-O, Supercond. Sci. Technol. 9:1015 (1996).

2. K. Fossheim, E. D. Tuset, T. W. Ebbesen, M. M. J. Treacy, and J. Schwartz, Enhanced flux pinning in $\mathrm{Bi}_{2} \mathrm{Sr}_{2} \mathrm{CaCu}_{2} \mathrm{O}_{8+x}$ superconductor with embedded carbon nanotubes, Physica $C 248: 195$ (1995).

3. S. Sengupta, V. R. Todt, K. C. Goretta, D. J. Miller, Y. L. Chen, and U. Balachandran, Effects of carbon additions to melt-processed $\mathrm{YBa}_{2} \mathrm{Cu}_{3} \mathrm{O}_{\mathrm{x}}$ and $\mathrm{Bi}_{2} \mathrm{Sr}_{2} \mathrm{CaCu}_{2} \mathrm{O}_{\mathrm{x}}$ compacts, IEEE Trans. Appl. Supercond. 7:1727 (1997).

4. S. Sengupta, V. R. Todt, P. Kostic, Y. L. Chen, M. T. Lanagan, and K. C. Goretta, Flux pinning in high- $\mathrm{T}_{\mathrm{c}}$ superconductors through addition of nanophase oxides, Physica $C$ 264:34 (1996).

5. D. Shi, M. S. Boley, U. Welp, J. G. Chen, and Y. Liao, Flux pinning by precipitates in the $\mathrm{Bi}-\mathrm{Sr}-\mathrm{Ca}-\mathrm{Cu}-\mathrm{O}$ system, Phys. Rev. B 40:5255 (1989).

6. D. H. Kim, K. E. Gray, R. T. Kampwirth, J. C. Smith, D. S. Richeson, T. J. Marks, J. H. Kang, $\mathrm{J}$. Talvacchio, and $\mathrm{M}$. Eddy, Effect of $\mathrm{Cu}-\mathrm{O}$ layer spacing on the magnetic field induced resistive broadening of high-temperature superconductors, Physica C 177:431 (1991).

7. P. E. Kazin, M. Jansen, A. Larrea, G. F. de la Fuente, and Yu. D. Tretyakov, Flux pinning improvement in $\mathrm{Bi}-2212$ silver sheathed tapes with submicron $\mathrm{SrZrO}_{3}$ inclusions, Physica $C$ 253:391 (1995).

8. Y. Tanaka, F. Matsumoto, H. Maeda, and M. Ishizuka, Improved $J_{c}$ property of Bi2223 tapes made using $\mathrm{AgCu}$ alloy-sheath doped with $\mathrm{Ti}, \mathrm{Zr}, \mathrm{Hf}$ or Au, IEEE Trans. Appl. Supercond. 5:1158 (1995).

9. K. C. Goretta, V. R. Todt, D. J. Miller, M. T. Lanagan, Y. L. Chen, U. Balachandran, J. Guo, and J. A. Lewis, Engineered flux-pinning centers in $\mathrm{Bi}_{2} \mathrm{Sr}_{2} \mathrm{CaCu}_{2} \mathrm{O}_{\mathrm{x}}$ and $\mathrm{TlBa}_{2} \mathrm{Ca}_{2} \mathrm{Cu}_{3} \mathrm{O}_{\mathbf{X}}$ superconductors, J. Electron. Mater. 24:1961 (1995).

10. P. Majewski, The use of phase diagrams for the engineering of flux pinning centres in $\mathrm{Bi}_{2} \mathrm{Sr}_{2} \mathrm{CaCu}_{2} \mathrm{O}_{x}$ ceramics, Appl. Supercond. 3:289 (1995).

11. H.-L. Su, P. Majewski, and F. Aldinger, Precipitation and pinning in $\mathrm{Pb}$ doped Bi2212 ceramics, Physica C 249:241 (1995).

12. P. Yang and C. M. Lieber, Nanorod-superconductor composites: a pathway to materials with high critical current densities, Science 273:1836 (1996).

13. W. Wei, Y. Sun, J. Schwartz, K. C. Goretta, U. Balachandran, and A. Bhargava, Preparation and properties of nanosize $\mathrm{TiO}_{2}-$ and $\mathrm{MgO}$-doped $\mathrm{Bi}_{2} \mathrm{Sr}_{2} \mathrm{CaCu}_{2} \mathrm{O}_{\mathrm{x}}$ tapes, IEEE Trans. Appl. Supercond. 7:1556 (1997).

14. I. Chong, Z. Hiroi, M. Izumi, J. Shimoyama, Y. Nakayama, K. Kishio, T. Terashima, Y. Bando, and $\mathrm{M}$. Takano, High critical-current density in the heavily $\mathrm{Pb}-$ doped $\mathrm{Bi}_{2} \mathrm{Sr}_{2} \mathrm{CaCu}_{2} \mathrm{O}_{8}+\delta$ superconductor: generation of efficient pinning centers, Science 276:770 (1997).

15. K. C. Goretta, B. P. Brandel, M. T. Lanagan, J. G. Hu, D. J. Miller, S. Sengupta, J. C. Parker, M. N. Ali, and N. Chen, Reactive nanophase oxide additions to melt-processed high- $T_{\mathrm{C}}$ superconductors, IEEE Trans. Appl. Supercond. 5:1309 (1995).

16. J. C. Parker, Nanophase Technologies Corporation, Burr Ridge, IL, private communication (1995).

17. H. Gleiter, Nanocrystalline materials, Prog. Mater. Sci. 33:223 (1989).

18. I. Bloom, J. R. Frommelt, M. C. Hash, M. T. Lanagan, C.-T. Wu, and K. C. Goretta, Solid state synthesis of $\mathrm{Bi}_{2} \mathrm{Sr}_{2} \mathrm{CaCu}_{2} \mathrm{O}_{\mathrm{x}}$ superconductor, Mater. Res. Bull. 26:1269 (1991).

19. C.-T. Wu, K. C. Goretta, and R. B. Poeppel, Effect of processing parameters on critical current density of $\mathrm{Ag}$-clad $\mathrm{Bi}_{2} \mathrm{Sr}_{2} \mathrm{CaCu}_{2} \mathrm{O}_{x}$ tapes, Appl. Supercond. 1:33 (1993).

20. E. E. Hellstrom, Important considerations for processing Bi-based high-temperature superconducting tapes and films for bulk applications, MRS Bull. 17[8]:45 (1992).

21. G. Villard, D. Pelloquin, A. Maignan, and A. Wahl, Evidence of enhanced pinning properties in optimally doped single $\mathrm{Bi}_{2} \mathrm{Sr}_{2} \mathrm{Ca}_{1-\mathrm{x}} \mathrm{Y}_{\mathrm{X}} \mathrm{Cu}_{2} \mathrm{O}_{8+\delta}$ crystals, Appl. Phys. Lett. 69:1480 (1996).

22. T. G. Holesinger, $\mathrm{Al}_{2} \mathrm{O}_{3}$ additions for isothermal melt processing of $\mathrm{Bi}_{2} \mathrm{Sr}_{2} \mathrm{CaCu}_{2} \mathrm{O}_{\mathrm{x}}, J$. Mater. Res. 11:2135 (1996). 
23. T. W. Li, R. J. Drost, P. H. Kes, C. Traeholt, H. W. Zandbergen, N. T. Hien, A. A. Menovsky, and J. J. M. Franse, Enhanced flux pinning in $\mathrm{Bi}-2212$ single crystals by planar defects introduced via Tisubstitution, Physica C 274:197 (1997).

24. J.-C. Grivel, A. Jeremie, and R. Flukiger, The influence of $\mathrm{TiO}_{2}$ additions on the formation and the superconducting properties of the $(\mathrm{Bi}, \mathrm{Pb})_{2} \mathrm{Sr}_{2} \mathrm{Ca}_{2} \mathrm{Cu}_{3} \mathrm{O}_{10-y}$ phase, Supercond. Sci. Technol. 8:41 (1995).

25. M. Ishizuka, $\mathrm{Y}$. Tanaka, and $\mathrm{H}$. Maeda, Superconducting properties and microstructures of $\mathrm{Bi}-2223$ $\mathrm{Ag}-\mathrm{Cu}$ alloy sheathed tapes doped with $\mathrm{Ti}, \mathrm{Zr}$ or Hf, Physica C 252:339 (1995).

26. M. Xu, University of Chicago, unpublished information (1997).

27. H. M. Seyoum, J. M. Habib, L. H. Bennett, W. Wong-Ng, A. J. Shapiro, and L. J. Schwartzendruber, Superconducting properties of $\mathrm{Bi}_{2-\mathrm{x}-\mathrm{y}} \mathrm{Pb}_{\mathrm{x}} \mathrm{Sn}_{\mathrm{y}} \mathrm{Sr}_{2} \mathrm{Ca}_{2} \mathrm{Cu}_{3} \mathrm{O}_{2}$, Supercond. Sci. Technol. 3:616 (1990).

28. Y. L. Chen and R. Stevens, The effect of tin dopant on the phase formation and superconductivity in $\mathrm{Bi}(\mathrm{Pb})-\mathrm{Sr}-\mathrm{Ca}-\mathrm{Cu}-\mathrm{O}$, J. Mater. Sci.: Mater. Electron. 1:197 (1990). 